\title{
Developmental Changes in Diastolic Ventricular Interaction
}

\author{
BOHDAN M. MINCZAK, MARLA R. WOLFSON, WILLIAM P. SANTAMORE, AND \\ THOMAS H. SHAFFER \\ Department of Physiology and Pediatrics, Temple University School of Medicine, Philadelphia, PA 19140 and \\ Department of Cardiology, Bowman Gray School of Medicine, Winston-Salem, NC 27103
}

\begin{abstract}
Developmental changes in the myocardial diastolic ventricular interaction of hearts excised from 12 preterm (126 $\pm 0.8 \mathrm{SE}$ days gestation; term $=147$ days) and eight newborn ( $2.5 \pm 0.2 \mathrm{SE}$ days postnatal age) lambs were evaluated in vitro. The excised hearts were immersed in a cold cardioplegic solution during which time compliant balloon catheters were inserted into the right and left ventricles through the pulmonary artery and aorta, respectively. The catheters were alternately connected to an infusion pump and appropriate transducers in order to obtain simultaneous biventricular pressure and volume measurements as the volume of each ventricle was varied. Computerized analysis of the pressure and volume recordings was used to determine right and left ventricular free wall compliance, ventricular septal compliance, and pressure and volume transfer functions. Ventricular septal compliance was significantly less than the free wall compliances within both groups. Ventricular septal compliance $(p<0.05)$ and transfer functions $(p<0.05)$ in the preterm were significantly lower than in the newborn. No significant differences in ventricular free wall compliances were found between or within age groups. These findings demonstrate an increase in ventricular coupling and functional interaction with development, potentially attributable to an increase in septal compliance with development. (Pediatr Res 23: 466-469, 1988)
\end{abstract}

Abbreviation

HW, heart weight

The right and left myocardial ventricles are in direct anatomical apposition and share a common deformable wall, the interventricular septum. Because of this anatomical relationship it is possible for pressure-volume changes in one ventricle to effect pressure-volume changes in the contralateral ventricle. This phenomenon of transferring pressure and/or volume changes from one ventricle to the adjacent ventricle, directly through the myocardium, independent of neural, circulatory, or humoral effects is termed ventricular interaction (1-3). Ventricular interaction occurs during both diastole and systole.

Ventricular interaction in the adult myocardium has been well described by theoretical $(4,5)$ and experimental models $(5-7)$ Other studies have identified transeptal pressure gradients $(8,9)$

Received April 27, 1987; accepted January 6, 1988.

Correspondence and reprint requests B. M. Minczak, Ph.D., c/o T. H. Shaffer Ph.D., Department of Physiology, Temple University School of Medicine 3420 North Broad Street, Philadelphia, PA 19140.

Supported in part by NIH Grant HL 30525, HL 36068, and 5T32HL07414-07 and the relative compliances of the septum and free walls $(5,10)$ as the primary determinants of ventricular interaction.

Little is known regarding ventricular interaction in the preterm and newborn infant (18). Previous studies have shown that circulatory patterns change with development $(11,12)$. At birth circulation changes from a parallel to a series circuit upon closure of the ductus arteriosus and foramen ovale causing alterations in the transeptal pressure gradients and volume loads seen by each ventricle. Subsequent age-related alterations in the thickness (1316) and compliance $(17,18)$ of the ventricular free walls and septum have been demonstrated. In addition the developmental changes in myocardial compliance have been correlated to ultrastructural $(19,20)$ differences in the composition of the myocytes $(17,20)$.

The current literature offers limited data with respect to ventricular interaction in the developing heart. The first objective herein was to compare developmental changes in myocardial compliance and diastolic ventricular interdependence in preterm and newborn lamb hearts. Developmental changes in ventricular interaction were also correlated with maturational changes in wall compliances. Finally, based on the data presented herein as well as force balance considerations across the interventricular septum and wall compliances, we have attempted to explain alterations in ventricular function that occur during development.

\section{METHODS}

Animal preparation. Two experimental groups were examined: the first was comprised of 12 preterm lambs $(126 \pm 0.8$ SE days gestation; term $=147$ days, weighing $2.79 \pm 0.2 \mathrm{SE} \mathrm{kg}$ with heart weights of $18.8 \pm 0.4 \mathrm{SE} \mathrm{g}$ ), delivered by hysterotomy and the second group consisted of eight newborn lambs $(2.5 \pm 0.2 \mathrm{SE}$ days postnatal age, weighing $3.43 \pm 0.2 \mathrm{SE} \mathrm{kg}$ with heart weights of $23.9 \pm 2.0 \mathrm{SE} \mathrm{g}$ ), previously delivered vaginally. The pregnant ewes used for obtaining the preterm animals were given $500 \mathrm{mg}$ of ketamine hydrochloride intramuscularly before induction of spinal anesthesia with $4 \%$ bupivicaine epidurally.

Lambs in both groups were euthanized with a lethal dose of magnesium chloride ( $50 \mathrm{mg} / \mathrm{kg}$ body weight intravenously) and their hearts immediately excised, via a mid-sternal thoracotomy. The hearts were then placed in a cold $\left(10^{\circ} \mathrm{C}\right)$ cardioplegic solution (sodium chloride $602 \mathrm{mg} / 100 \mathrm{ml}$, calcium chloride 23.1 $\mathrm{mg} / 100 \mathrm{ml}$, potassium chloride $119.3 \mathrm{mg} / 100 \mathrm{ml}$, sodium bicarbonate $37 \mathrm{mg} / 100 \mathrm{ml}$, mannitol $1250 \mathrm{mg} / 100 \mathrm{ml}$, dextrose 300 $\mathrm{mg} / 100 \mathrm{ml}$ ) to retard postmortem deterioration and prevent any active tension development (21). The coronary arteries were retroperfused with cardioplegic solution via a small lumen catheter, which was inserted into the coronary ostia at the aortic root. This was performed to further attenuate metabolic and postmortem compliance changes. The ventricles were then instrumented with balloon catheters fabricated from two very compliant bal- 
loons attached to rigid PE 240 (i.d. $0.066^{\prime \prime}$; o.d. $0.095^{\prime \prime}$ ) tubing. The balloons were previously overinflated $(+100 \mathrm{ml})$ with water for several days before use to alleviate any significant back pressure development. Deflated balloon catheters were placed retrograde via the pulmonary artery and aorta into the right and left ventricles and ligated into place. Where indicated the chordae tendinae were severed to ensure proper balloon contact with the myocardial walls. Proper balloon placement was ensured by manual and visual inspection of the heart as cold water was infused and withdrawn via a syringe into the catheterized ventricles. The balloon catheters were then filled with an "unstressed" volume (i.e. producing a pressure of zero) of cold water. The catheter tip within the balloon was placed to approximate the middle of the ventricle. The instrumented heart was then connected to a manifold of stopcocks which joined an infusion pump (Harvard Apparatus), to the right ventricular balloon and pressure transducer (Statham P23db) and the left ventricular balloon to a pressure transducer. A collection chamber was hung from a force transducer (Biocom) calibrated to yield volume changes for a given weight change (Fig. 1). Apparatus and procedure allowed simultaneous pressure and volume measurements in the ventricles as the volume of one ventricle was varied.

Experimental protocol. A set of two measurement runs were made, one with the responding ventricle isovolumic and the other with the responding ventricle isobaric or ejecting. In the first run the stopcock (Fig. 1) was closed rendering the left or "responding" ventricle isovolumic. The infusion pump was set to a known flow rate $(3.9 \mathrm{ml} / \mathrm{min})$ and activated, infusing cold water into the right or "driving" ventricle. The right and left ventricular pressures during the infusion were measured by the respective pressure transducers. Right and left ventricular pressure changes were recorded on an Electronics for Medicine VR6 recorder. The right ventricular volume change as a result of the infusion was determined by calculating the product of the known infusion rate and the duration of the infusion. The duration of the infusion was determined from the time marks on the hardcopy trace.

During the second run the stopcock (Fig. 1) was opened allowing left ventricular volume to change, while maintaining left ventricular pressure constant. Once again the infusion pump was activated but now the left ventricular volume changed. As the right ventricular pressure and volume increased, cold water was ejected from the left ventricular catheter into the volume collection chamber. This volume change and the concomitant right ventricular pressure change were also recorded. The concomitant right ventricular volume change was determined as in

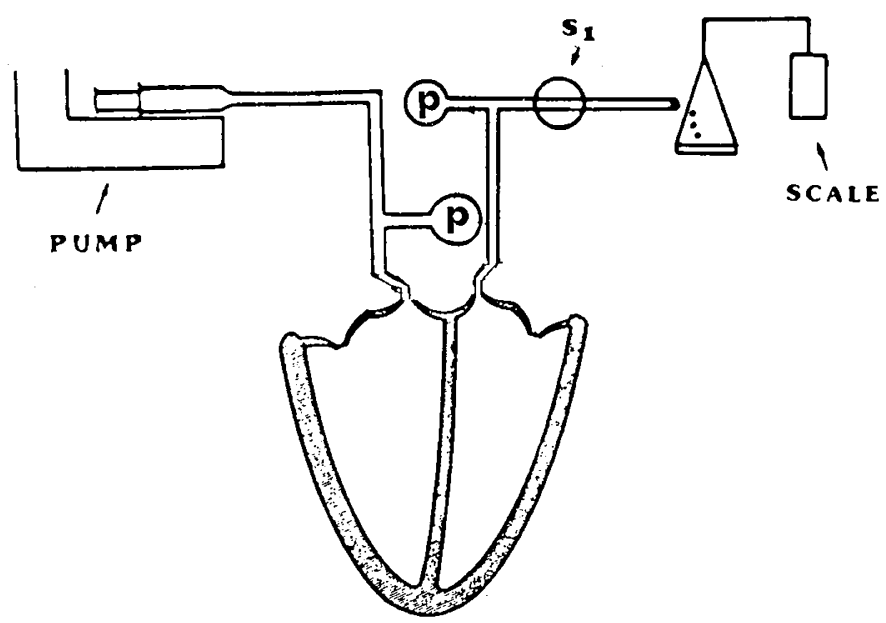

Fig. 1. Experimental set-up. Components: Harvard infusion pump; Statham pressure transducers $(P)(\mathrm{P} 23 \mathrm{db})$; balloon catheterized heart volume collection chamber; scale, force transducer (Biocom); $S 1$, stopcock. run one. Each run was performed three times to obtain multiple measurements. Subsequently the catheters were reversed and the measurements repeated. The entire experimental protocol spanned 60 to $75 \mathrm{~min}$. To test the viability and stability of the preparation, the first set of measurements (both isovolumic and isobaric) were repeated in three animals at the end of the experimental protocol to determine differences in either transfer functions or compliances as a function of time. The temperature and $\mathrm{pH}$ of the cardioplegic solution remained constant for the duration of the protocol.

Compliance and transfer function determinations. As previously described (4), the volume ejected from the left ventricle during the right ventricular infusion was assumed to be the septal volume displacement. As the pressure rose in the right ventricle during run 2 and pushed the septum into the left ventricle, the left ventricular pressure remained constant as a result of the fluid ejection. This volume ejected from the left ventricle was quantified and later subtracted from the total volume injected into the right ventricle, yielding the volume displacement of the right ventricular free wall. Subsequently the right free wall and septal volume changes were divided by the right ventricular pressure change to determine their respective compliances. To determine left free wall compliance values a similar approach was used.

To quantify the degree of interaction between the myocardial ventricles four previously described transfer function values were determined (4). The pressure transfer functions (dpl/dpr and $\mathrm{dpl} / \mathrm{dvr}$ ) represent a change in left ventricular pressure for a change in right ventricular pressure or volume. These were determined from the measurements of run 1 made during the right ventricular infusion whereas the left ventricular volume was held constant. The volume transfer functions (dvl/dpr and $\mathrm{dvl} / \mathrm{dvr}$ ) were determined from measurements of run 2 made during the right ventricular infusion with the left ventricular pressure constant.

Computerized data analysis. The above data were computer (Apple-II Plus) analyzed by using an Apple digitizing pad and cross-haired cursor. Upon tracing the analog pressure and volume traces with the cursor the computer converted these signals into digital pressure and volume values after referencing the pressure and volume calibration signals of $30 \mathrm{~mm} \mathrm{Hg}$ and $1 \mathrm{ml}$ full scale, respectively. These were input at the beginning of the experiment. These data were then stored on an electromagnetic disk for future analysis.

Compliance and transfer function data were reduced using specifically designed computer software. Using a sliding second order polynomial fit (22), derivatives of the pressure and volume changes were calculated and appropriately divided point by point to yield the individual relative wall compliances and transfer functions. All compliance and transfer function data were reported at a "driving" ventricular pressure of $5.5 \mathrm{~mm} \mathrm{Hg}$ in the preterm and newborn infants to describe diastolic ventricular interaction $(23,24)$. The responding isobaric ventricle was maintained at $3-6 \mathrm{~mm} \mathrm{Hg}$.

Statistical considerations. Compliance data from both the preterm and newborn groups were analyzed for inter- and intragroup differences by using a two-way analysis of variance with post hoc (Tukey) test where applicable. Pressure and volume transfer functions were evaluated for intergroup differences by an unpaired Student's $t$ test.

\section{RESULTS}

With respect to differences in wall compliance (Fig. 2), the septal compliance of the preterm group $(0.37 \pm 0.09 \mathrm{SE} \mathrm{ml} / \mathrm{mm}$ $\mathrm{Hg} / \mathrm{g} \mathrm{H}$.W. $\left.\times 10^{-3}\right)$ was significantly less $(p<0.03)$ than the preterm right $\left(2.25 \pm 0.45 \mathrm{SE} \mathrm{ml} / \mathrm{mm} \mathrm{Hg} / \mathrm{g} \mathrm{H} . \mathrm{W} . \times 10^{-3}\right)$ and left $\left(2.69 \pm 0.38 \mathrm{SE} \mathrm{ml} / \mathrm{mm} \mathrm{Hg} / \mathrm{g} \mathrm{H} . W . \times 10^{-3}\right)$ free wall compliances. The preterm right and left free wall compliances were similar. Within the newborn group, the septal compliance of the newborn group $(1.21 \pm 0.45 \mathrm{SE} \mathrm{ml} / \mathrm{mm} \mathrm{Hg} / \mathrm{g} \mathrm{H} . W . \times$ 
$10^{-3}$ ) was less than the compliance of either the newborn myocardial right free wall $(3.45 \pm 0.94 \mathrm{SE} \mathrm{ml} / \mathrm{mm} \mathrm{Hg} / \mathrm{g} \mathrm{H} . W . \times$ $\left.10^{-3}\right)$ or left free wall $(2.96 \pm 0.91 \mathrm{SE} \mathrm{ml} / \mathrm{mm} \mathrm{Hg} / \mathrm{g} \mathrm{H}$.W. $\times$ $10^{-3}$ ). In addition, no difference was demonstrated between the compliances of the newborn right and left free walls. Furthermore, on reversing the catheters and changing the left ventricle to the "driving" ventricle, preterm septal compliance was found to be $\left(0.38 \pm 0.09 \mathrm{SE} \mathrm{ml} / \mathrm{mm} \mathrm{Hg} / \mathrm{g} \mathrm{H} . W . \times 10^{-3}\right)$ and that of the newborn was $\left(1.09 \pm 0.29 \mathrm{SE} \mathrm{ml} / \mathrm{mm} \mathrm{Hg} / \mathrm{g} \mathrm{H} . \mathrm{W} . \times 10^{-3}\right)$. No differences in the mean values of the compliances of the septae were evident regardless of which ventricle was the "driving" ventricle.

When assessing age-related differences between the two groups, preterm septal compliance $(0.37 \pm 0.09 \mathrm{SE} \mathrm{ml} / \mathrm{mm} \mathrm{Hg} / \mathrm{g} \mathrm{H}$.W. $\left.\times 10^{-3}\right)$ was significantly less $(p<0.03)$ than newborn septal compliance $\left(1.21 \pm 0.35 \mathrm{SE} \mathrm{ml} / \mathrm{mm} \mathrm{Hg} / \mathrm{g} \mathrm{H}\right.$.W. $\left.\times 10^{-3}\right)$. However, no difference between groups was seen for the left or right wall compliances.

As previously documented (4), the relative myocardial free wall and septal compliances can be used in determining the degree of ventricular interaction (Table 1) and are expressed as ratios. Briefly, the degree of pressure-volume interactions between the ventricles is dependent on the relative compliances of the ventricular walls and septum to each other and the balance of forces across the interventricular septum. Based on these premises, the previous investigators derived a system of equations using the individual wall compliances expressed as ratios to calculate transfer function values that express or quantify the degree of pressure-volume interaction between the ventricles. We therefore computed the left free wall to septal, right free wall to septal, and left free wall to right free wall compliance ratios (Fig. 3 ) and analyzed them with respect to developmental age. In the preterm hearts as depicted in Figure 3, the left free wall to septal compliance ratio (8.32) and the right free wall to septal compliance ratio (7.96) were significantly $(p<0.01)$ greater than the left wall to right wall ratio (1.14). However, no intragroup difference was found between the left wall to septal and right wall to septal compliance ratios. Similarly, within the newborn group both the right (3.83) and left (2.93) free wall to septal compliance ratios were significantly greater $(p<0.01)$ than the left wall to right wall compliance ratio $(0.83)$. No intragroup

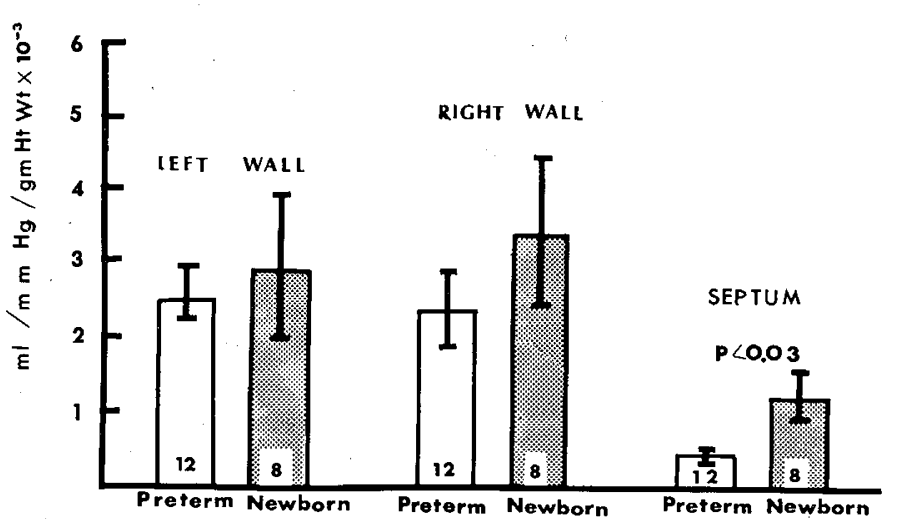

Fig. 2. Effect of development on wall compliance. A comparison of preterm and newborn right and left free wall and septal compliance. difference between the left wall to septal and right wall to septal compliance ratios was demonstrated.

When analyzing developmental changes in relative wall compliance ratios, the left wall to septal compliance ratio (8.32) was found to be significantly greater $(p<0.02)$ in the preterm group as compared to the newborn group (2.93). Similarly the right wall to septal compliance ratio (7.96) of the preterm group was found to be greater $(p<0.05)$ than this ratio in the newborn group (3.83). There was no difference between the newborn and preterm left wall to right wall compliance ratio.

Table 2 illustrates the four experimentally measured transfer functions for the two age groups. The transfer functions presented herein represent a left ventricular response for a right ventricular perturbation. As evident from Table 2 all four transfer functions in the preterm group were significantly less $(p<0.05)$ than the newborn transfer function values.

On completion of the experimental protocol the initial measurements (isovolumic and isobaric) were repeated in three animals to test the stability of the preparation. The transfer functions measured at the end of the protocol were as follows: $\mathrm{dpr} / \mathrm{dpl}=$ $0.142 \pm 0.021 \mathrm{SE}, \mathrm{dpr} / \mathrm{dvl}=0.110 \pm 0.009 \mathrm{SE}, \mathrm{dvr} / \mathrm{dpl}=0.329$ $+0.055 \mathrm{SE} \times 10^{-3}$ and $\mathrm{dvr} / \mathrm{dvl}=0.138 \pm 0.026 \mathrm{SE}$ for the preterm group; and $\mathrm{dpr} / \mathrm{dpl}=0.327 \pm 0.020 \mathrm{SE}, \mathrm{dpr} / \mathrm{dvl}=$ $0.175 \pm 0.028 \mathrm{SE}, \mathrm{dvr} / \mathrm{dpl}=1.27 \pm 0.29 \mathrm{SE} \times 10^{-3}$, and $\mathrm{dvr} /$ $\mathrm{dvl}=0.230 \pm 0.029 \mathrm{SE}$ for the newborn group. These data were not significantly different than the initial measurements shown in Table 2; thereby, demonstrating the reproducibility and sensitivity of the technique.

\section{DISCUSSION}

The results herein showed that septal compliance of the preterm was significantly less than that of the newborn, suggesting a possible mechanism for the observed decrease in ventricular interaction in the younger animals. In addition, our data demonstrated that the septal compliance of each group was less than the compliance of the ventricular free walls. However, our data

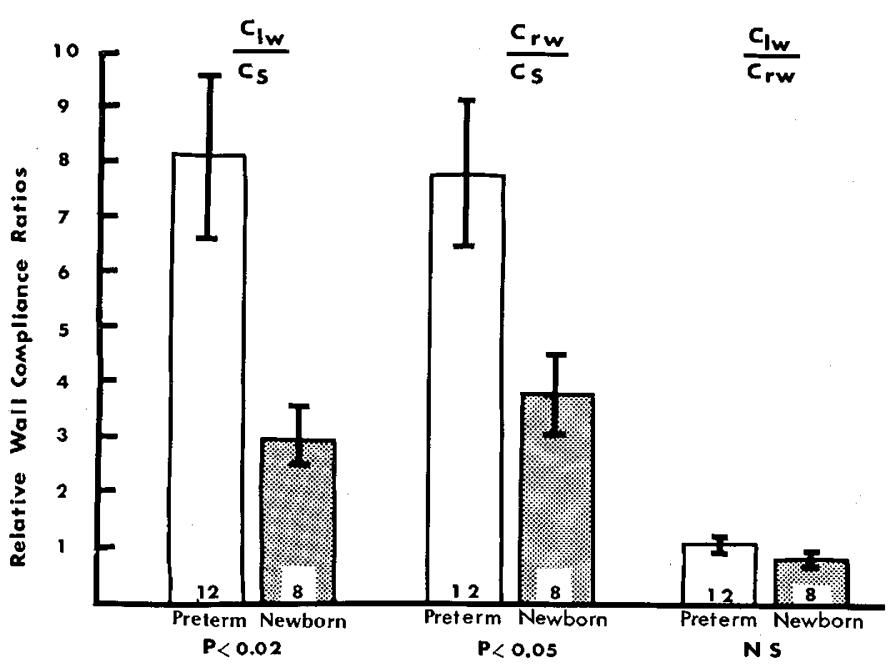

Fig. 3. Free wall and septal compliance ratios from preterm and newborn lambs.

Table 1. Equations for computation of theoretical transfer functions

\begin{tabular}{cl}
\hline Left ventricular pressure transfer function & Left ventricular volume transfer function \\
\hline $\mathrm{dpl} / \mathrm{dpr}=\frac{1}{1+\left(\mathrm{C}_{\mathrm{lw}} / \mathrm{C}_{\mathrm{s}}\right)}$ & $\mathrm{dvl} / \mathrm{dpl}=\mathrm{C}_{\mathrm{s}}$ \\
$\mathrm{dpl} / \mathrm{dvr}=\frac{\mathrm{C}}{\left(\mathrm{C}_{\mathrm{rw}}\right)\left(\mathrm{C}_{\mathrm{s}}\right)+\left(\mathrm{C}_{\mathrm{rw}}\right)\left(\mathrm{C}_{\mathrm{lw}}\right)+\left(\mathrm{C}_{\mathrm{lw}}\right)\left(\mathrm{C}_{\mathrm{s}}\right)}$ & $\mathrm{dvl} / \mathrm{dvr}=\frac{1}{1+\left(\mathrm{C}_{\mathrm{rw}} / \mathrm{C}_{\mathrm{s}}\right)}$ \\
\hline
\end{tabular}


Table 2. Experimental ventricular transfer functions for preterm and newborn hearts (mean $\pm S E$ )

\begin{tabular}{|c|c|c|c|c|}
\hline & \multicolumn{2}{|c|}{$\begin{array}{l}\text { Left ventricular pressure } \\
\text { transfer function }\end{array}$} & \multicolumn{2}{|c|}{$\begin{array}{l}\text { Left ventricular volume } \\
\text { transfer function }\end{array}$} \\
\hline & $\mathrm{dpl} / \mathrm{dpr}$ & $\begin{array}{c}\mathrm{dpl} / \mathrm{dvr} \\
(\mathrm{mm} \mathrm{Hg} / \mathrm{ml} / \mathrm{g} \\
\mathrm{HW})\end{array}$ & $\begin{array}{c}\mathrm{dvl} / \mathrm{dpr} \\
\left(\times 10^{-3} \mathrm{ml} / \mathrm{mm}\right. \\
\mathrm{Hg} / \mathrm{g} \mathrm{HW})\end{array}$ & $\mathrm{dvl} / \mathrm{dvr}$ \\
\hline Preterm & $\begin{array}{r}0.147 \\
\pm 0.026\end{array}$ & $\begin{array}{r}0.119 \\
\pm 0.012\end{array}$ & $\begin{array}{r}0.318 \\
\pm 0.062\end{array}$ & $\begin{array}{r}0.148 \\
\pm 0.022\end{array}$ \\
\hline Newborn & $\begin{array}{l}0.324^{*} \\
\pm 0.024\end{array}$ & $\begin{aligned} & 0.175 \dagger \\
\pm & 0.028\end{aligned}$ & $\begin{array}{l}1.13 \dagger \\
\pm 0.36\end{array}$ & $\begin{aligned} & 0.235 \dagger \\
& \pm 0.032 \\
&\end{aligned}$ \\
\hline
\end{tabular}

$* p<0.001$.

$\dagger p<0.05$.

demonstrated no difference in the compliances of the individual free walls within or between the preterm and newborn groups.

Based on these findings we would expect whole chamber compliance data for both the right and left ventricles to show no difference in the distensibility of the two chambers within each experimental group. Romero et al. (20) studying whole chamber compliances of the fetal and newborn heart indeed found that the right and left ventricles of the fetus had similar compliances at pressures comparable to those reported herein. Furthermore, our data suggest that the hearts of newborns would have ventricular chambers that are more compliant than the ventricles of the preterms. The data presented by these investigators demonstrated that newborn ventricles were more compliant than preterm ventricles and these data demonstrated that no significant difference existed between the right and left ventricular compliances at filling pressures comparable to ours.

In contrast, studies reporting data from isolated myocardial muscle tissue have noted that overall myocardial tissue compliances increase with development $(17,18)$. However, it is difficult to make direct comparisons with this previous work because of differing techniques and instrumentation. Because ventricular interaction is affected by the relative differences in wall compliances and the balance of forces across the septum $(4,5)$, we analyzed age-related changes in wall compliance ratios (Fig. 3). As shown there were developmental differences in the wall compliance ratios of the two experimental groups. The relative free wall to septal compliance ratios of the preterm group were significantly greater than those of the newborn, attributable to the lower septal compliance of the preterm.

Inasmuch as the interventricular septum is anatomically in contact with both ventricles, it theoretically dominates the degree of transfer between the ventricles (4). Therefore, any change that occurs in its distensibility will markedly affect the degree of pressure/volume information transferred between the ventricles. Albeit that there are other modes of information transfer between the ventricles, we only examined the degree of transfer between the ventricles through the myocardium proper, i.e. septum and common fibers, as our model describes. The effects of serial interaction and pericardial effects will require subsequent investigations to determine their respective roles in the overall circulatory picture. Experimentally determined pressure-volume transfer functions (Table 2 ) showed that preterm values were less $(p<0.05)$ than those of the newborn group. This finding demonstrates that the mechanical events in one ventricle have less effect on the opposite ventricle in immature lamb hearts, as compared to newborn lamb hearts, thus confirming developmental differences in diastolic ventricular interaction associated with changes in septal compliance.

Age-related changes in ventricular interaction are consistent with other developmental alterations in the circulatory system. Before birth, the right and left ventricles pump in parallel (24), circulating blood from the great veins to the aorta and virtually bypassing the lungs. Left ventricular preload, and therefore out- put, is essentially independent of right ventricular output $(25$, 26). The stiff septum of the fetus would enhance the parallel nature of the cardiovascular circuit. Postnatally the right ventricle pumps serially to the left ventricle through the pulmonary circuit and left ventricular output is no longer independent of right ventricular output. A more compliant septum in the newborn would conform suitably to a serial circuit allowing greater interaction between right and left ventricular outputs. This interaction would provide greater feedback between the ventricles and control over individual ventricular outputs, thus accommodating changes in systemic and pulmonary vascular resistance.

In conclusion this study indicates that there are developmental differences in the degree of diastolic ventricular interaction between the ventricles. The level of interaction increases with developmental age and is the result of an increase in interventricular septal compliance.

Acknowledgments. The authors thank Raymond B. Penn for reading and reviewing this manuscript. We also acknowledge Christine $\mathrm{H}$. Minczak for her assistance.

\section{REFERENCES}

1. Glantz SA, Parmley WW 1978 Factors which affect the diastolic pressurevolume curve. Circ Res 42:171-180

2. Janicki JS, Weber KT 1980 Factors influencing the diastolic pressure-volume relation of the cardiac ventricles. Fed Proc 39:133-140

3. Bove AA, Santamore WP 1981 Ventricular interdependence. Prog Cardiovasc Dis 23:365-388

4. Santamore WP, Shaffer TH, Hughes DA 1986 Theoretical and experimental model of ventricular interdependence. Basic Res Cardiol 81:529-537

5. Sungawa K, Maughan WL, Weisfeldt ML, Sagawa K 1982 Effect of systolic trans-septal pressure on septal elastance and ventricular cross talk. Circulation 64:IV-53

6. Elzinga G, Van Grondelle R, Westerhef N, Van Den Bos GC 1974 Ventricular interference. Am J Physiol 226:941-947

7. Mirsky I, Rankin JS 1979 The effects of geometry, elasticity and external pressures on the diastolic pressure-volume and stiffness relations: how important is the pericardium? Circ Res 44:601-611

8. Guzman P, Maughan WL, Eation LW 1979 Trans-septal pressure gradient with leftward septal displacement during ventricular loading in man. Circulation 60:II-122

9. Santamore WP, Lynch PR, Meier GM, Bove AA 1976 Myocardial interaction between the ventricles. J Appl Physiol 41:362-368

10. Little WC, Badke FR, O'Rourke RA 1984 Effect of right ventricular pressure on the end-diastolic left ventricular pressure-volume relationship before and after chronic right ventricular pressure overload in dogs without pericardia. Circ Res 54:719-730

11. Rudolph AM, Heymann MB 1970 Circulatory changes during growth in the fetal lamb. Circ Res 27:289-299

12. Rudolph A 1940 Changes in circulation after birth. Circulation $41: 343$

13. Keen EN 1955 The postnatal development of the human cardiac ventricles. $J$ Anat (Lond) 89:484-502

14. Hort W 1966 The normal heart of the fetus and its metamorphosis in the transition period. In: Cassels DE (ed). The Heart and Circulation in the Newborn Infant. Grune and Stratton, New York, pp 210-224

15. Emery JL, MacDonald MS 1960 The weight of the ventricles in the later weeks of intrauterine life. Br Heart J 22:563-570

16. Recavarren S, Avia-Stella J 1964 Growth and development of the ventricular myocardium from birth to adult life. Br Heart J 26:187-192.

17. Friedman WF 1972 The intrinsic properties of the developing heart. Prog Cardiovasc Dis XV:87-111

18. Romero T, Covell J, Friedman W 1972 A comparison of pressure-volume relations of the fetal, newborn and adult heart. Am J Physiol 222:1285-1290

19. Friedman WF, Cooper C, Su JS 1970 The intrinsic physiological properties of the developing myocardium. Proc Am Pediatr Soc 80:154

20. Romero T, Friedman WF, and Covell JW 1970 The pressure-volume relations of the fetal, newborn and adult heart. Circulation 42(suppl III):52

21. Rosenkranz ER, Buckberg GD 1983 Myocardial protection during surgical coronary reperfusion. J Am Coll Cardiol 1:1235-1246

22. Marble AE, McIntyre CM, Hastings-James R, Hor CW 1981 A comparison of digital algorithms used in computing the derivative of left ventricular pressure. IEEE Trans Biomed Eng BME 28:524-528

23. Arcilla RA, Oh W, Lind J, and Blankenship W 1966 Portal and atrial pressures in the newborn period. Acta Paediatr Scand 55:615

24. Anderson AWP, Manring A, Glick KL, Crenshaw CC Jr 1982 Biophysics of the developing heart III. A comparison of the left ventricular dynamics of the fetal and neonatal heart. Am J Obstet Gynecol 143:195-203

25. Dawes GS, Mott JC and Widdicombe JG The foetal circulation in the lamb. J Physiol 126:563-587

26. Walsh SZ, Lind J 1978 The fetal circulation and its alteration at birth. In: Uwe S (ed) Perinatal Physiology. Plenum Medical Book Company, New York, pp 129-180 